\title{
School Gardening in Early Childhood Education in Oman: A pilot project with Grade 2 Students
}

\author{
Abdulla Ambusaidi', Rashid Al-Yahyai ${ }^{2}$, Subhashni Taylor ${ }^{3}$, Neil Taylor ${ }^{4 *}$ \\ ${ }^{1}$ College of Education, Sultan Qaboos University, Muscat, Oman, ${ }^{2}$ College of Agriculture and Marine Science, Sultan Qaboos University, Muscat, \\ Oman, ${ }^{3}$ College of Arts, Society and Education, James Cook University, Cairns, Queensland, Australia, ${ }^{4}$ School of Education, University of New \\ England, New South Wales, Australia.
}

*Corresponding Author: ntaylor6@une.edu.au

\section{ABSTRACT}

While school gardens are familiar in many Western contexts and research has reported significant pedagogical and affective is correct benefits of these resources, there is limited reporting of their use in non-western contexts. A pilot school gardening project involving a quasi-experimental mixed method design was undertaken in the Sultanate of Oman with several Grade 2 and Grade 7 classes to determine if this resource might provide benefits in this particular context. This paper reports on the findings for the Grade 2 cohort. While these findings were somewhat mixed and need to be treated tentatively given that the study was a pilot, they do suggest that school gardens in Oman could provide affective and possible health benefits for students. The potential health benefits could be particularly significant because the Omani population is beginning to exhibit a rapid increase in "lifestyle diseases," most notably diabetes and cardiovascular illnesses. These illnesses appear to be linked to poor dietary habits and a more sedentary lifestyle among the younger generation.

KEY WORDS: young learners; Oman; school gardening; pilot study; mixed-methods

\section{INTRODUCTION}

$\Delta$ number of research projects have demonstrated significant benefits from incorporating teacher-student care of school gardens into school curricula. Benefits include increased student understanding of science and, in particular, food production (Graham et al., 2005), mental well-being (Hoffman et al., 2004; Sheffield, 1992; Smith and Aldous, 1994), and physical health outcomes (Passy et al., 2011). Other identified benefits include enhanced interest in and aptitude for learning (Clark, 1977; Passy et al., 2011; Sheffield, 1992; Waliczek et al., 2001).

A previous paper, Ambusaidi et al. (2018), reported the findings of research conducted with Grade 7 students and their interactions with school gardens in Oman. This article reports on similar research with a cohort of students in Grade 2 (students aged 6-7) in an effort to determine if school gardens might have any benefits, both affective and in terms of learning outcomes, for younger students.

The overall project was a pilot study to assess the impact that school gardens could have on Omani students and wider community.

The major research question for the study was: Can school gardens be an effective pedagogical resource in schools within the Sultanate of Oman? Specifically:

1. Does school gardening improve students' content knowledge in science?

2. Does school gardening improve students' process skills in science?
3. Does school gardening encourage students to consume more fruit and vegetables as part of their everyday diet?

4. Does school gardening improve students' attitudes to science and agriculture?

Over the past decade, Oman has paid greater attention to not only increasing students' knowledge of and skills in agricultural science but also to encouraging better nutritional intake by students and the population in general. The former is driven by a need to increase food sustainability and the latter by the need to counter lifestyle diseases.

Conventionally, Oman has depended on revenue from oil reserves. Selling such reserves accounted for $84 \%$ of government revenue in 2016. However, in the face of dwindling oil reserves and reduced prices for oil on the global market, the government of Oman is seeking to diversify its economic base and to reduce its reliance on expatriate labor and imports of food. At present, Oman imports 50\% of its vegetables (Central Intelligence Agency, 2016). In 2011, an article titled "Food imported by Oman set to grow" in the Oman Daily Observer estimated that the country's rate of food imports would increase by $128 \%$ by 2020 , placing an unsustainable strain on the nation's budget.

The Omani Ministry of Agriculture and Fisheries is attempting to make Oman self-sufficient in food production, especially in terms of vegetables, fruits, milk products, and seafood. Several related projects are presently under development in cooperation with the private sector. Consequently, there is a need to prepare a new generation to be part of this initiative 
by introducing them to fruit and vegetable production through the development of school gardens.

Since His Majesty Sultan Qaboos bin Said came to power in 1970, Oman has increased its efforts to develop Oman's agricultural sector. Omani farms now receive significant government support, such as through the supply of seedlings, fertilizers, and pesticides and provision of machines for irrigation, tillage, and harvesting. Intensive farming is, however, only possible in the fertile coastal regions because much of the interior of Oman's 309,500 square-kilometer landmass is "sandy, treeless, and largely waterless" (Crystal and Peterson, 2016, p. 1).

Of concern is that Oman's largely coastal and urban population (Al-Moosa et al., 2006) displays little interest in employment in the agricultural sector. The 2012/2013 census showed that $32 \%$ of agricultural workers were expatriates, up from $25.1 \%$ in 2004/2005 (Omani Ministry of Agriculture and Fisheries, 2014). Such heavy reliance on expatriates is particularly concerning given that there is a drive by the government for "Omanization," partly to reduce the country's reliance on expatriate workers, which currently make up $40 \%$ of Oman's 3.35 million population, and partly to increase employment opportunities for Omani youth. Almost half the Omani population is under the age of 25 and, with Oman's population growth estimated at $2.05 \%$ per year, rising numbers of young Omanis are seeking entry to the workforce.

Revenue from oil reserves has been a significant boon in the nation's capacity to modernize, including modernization and improvement of health systems. The World Health Organization ranked Oman's public health system eighth best in the world in 2000 (WHO, 2000). Nevertheless, Oman has not escaped the trend of "lifestyle diseases" that often accompany modernization. Increased heart disease, high blood pressure, and diabetes have all become more prevalent, particularly in urban areas (Al-Moosa et al., 2006; Al Riyamai and Afifi, 2003; Ambusaidi et al., 2015). Increased rates of obesity in children have caused many parents to call for a ban on the sale of "junk" food in school canteens (Al Shaibany, 2011).

This project involving school gardens is, thus, set within a context of several initiatives taken by the Omani government to ready itself for a sustainable national future. Two student cohorts were participated in the study - those in Grade 2 and those in Grade 7. Another paper (Ambusaidi et al., 2018) discusses the findings concerning the Grade 7 students. This paper presents the findings relevant to the Grade 2 students.

\section{LITERATURE REVIEW AND THEORETICAL CONSIDERATIONS}

More than 150 years have passed since the benefits that gardening offers young children gained dedicated recognition among educators. In 1840, Fredrick Froebel developed the notion of teaching through gardening when he established a kindergarten dedicated to this pursuit (Bowker and
Tearle, 2007). Maria Montessori expanded on this idea in the early $20^{\text {th }}$ century. She found that access to gardens on preschool and school sites not only improved children's appreciation for nature but also enhanced their relationship skills and helped them to develop patience and responsibility for others and their surroundings. She saw gardening as an adjunct to the standard curriculum, especially in terms of promoting moral education (Montessori, 1964).

According to Marturano (1999), the underlying precept of school-based gardens is that of encouraging children to use all their senses to explore the world of plants and to value the place of plants in human history. Crisp et al. (2000) agreed with Marturano that school gardens offer a rich environment for experiential learning. Ozer (2007) concluded, from her review of school garden programs in the United States, that these programs can provide a variety of pathways into enhancing children's healthy development in terms of nutritional intake, academic engagement and achievement, and connection to the school. They can also, she noted, help to facilitate a positive school culture and strengthen ties between school, home, and community. The positive influence of school gardens on students' nutritional knowledge and extension of students' food choices have also been well-documented (Lavin et al., 1992; Ozer, 2007; Morgan et al., 2010; Knai, Pomerlau et al., 2006; Lineberger and Zajicek, 2000).

Morgan et al. (2010) contended that school vegetable gardens encourage children to eat more vegetables simply because they increase the children's experience to these foods as they plant, tend, harvest, and even cook them. Morgan et al. also emphasized that these activities can simultaneously build the life skills associated with gardening and cooking as well as ability to work cooperatively with others on real tasks. According to these authors, gardening fosters students' understanding and appreciation of how the natural world works (e.g., seasonality), where food comes from and the work that is required to produce it. Clark (1977) found that caring for plants helped to teach children responsibility. He pointed out that, as gardening requires children to respond to living things, it is one of the few school-based situations that offer an opportunity for teachers to develop this affective style of learning in their students.

Various studies indicate that school garden programs have the potential to improve children's learning in traditional curriculum subjects. A study carried out by Sheffield (1992), for example, showed an experimental group of gardening students gaining significantly higher scores than a control group of non-gardening students on standardized tests of mathematics and literacy.

Among the very few school garden projects in the Gulf and Middle East regions (there appear to be none relating to Oman) is one by Elzaanen (2010), undertaken in Gaza, which featured a garden-based intervention with 125 Grade 7 students. The findings, based on pre- and post-testing, showed that the students in the experimental groups outperformed the control 
groups in science achievement and understanding of science processes.

Teachers who featured in Passy et al. (2011) study of school garden projects in the UK were able to identify links between their students' garden-related activities and improvements in the children's understanding of science concepts such as taxonomy, habitats, and life cycles. The researchers also identified enhanced scientific skills (e.g., doing experiments), greater proficiency in scientific language, and improved mathematical skills, including those relating to estimation, measurement, and graph use.

Several studies (e.g., Hoffman et al., 2004, and Sheffield, 1992) have also documented positive associations between students' engagement in school gardening and their confidence and selfesteem. Underachieving students, especially, seem to benefit in this way, while students with learning disabilities report feeling more valued as individuals (Smith and Aldous, 1994). A USbased study of children participating in a school gardening program indicated that they developed better interpersonal skills and attitudes toward their schools (Waliczek et al., 2001).

One of the main advantages school gardens offer is the opportunity to teach core subjects (e.g., math, language, science, and arts) within a hands-on learning environment (Morris et al., 2002). The gardens, therefore, bring another tool to teachers' teaching repertoire. Furthermore, teachers can shape that tool to suit their teaching styles and objectives since they do not require gardening expertise to draw on the garden as a teaching medium, but can acquire gardening knowledge alongside their students (Graham et al., 2005).

As school gardens are a non-classroom-based initiative and are used as an adjunct to the standard curriculum, support from school staff (the school principal, especially) is essential to their success. Establishing and maintaining school gardens require time, funding, energy, and effort from both teachers and students (Hawe and Shiell, 2000). Ozer (2007) found, from her research review of school garden programs in the United States, that the most successful ones were those that were well supported by teaching and administrative staff and by parents and community volunteers. This type of support seemed to be a crucial success factor, no matter whether the garden was small in scope (e.g., several planter boxes) or comprised expansive plantings. Ozer also identified as another success factor, the extent to which a school had integrated the garden program into its standard curriculum.

The type of learning that occurs outside the classroom walls typically differs from formal classroom learning, most especially in terms of being less formal, being more socially interactive and offering students greater control over their own learning activities (Griffin, 2004; Scott, 1998). Bamberger and Tal (2006) reported that even when students have only limited choice over their learning activities, it advantages children's natural curiosity and so has sound engagement and learning outcomes. Outside learning environments also let students actively participate with one another in the learning experience and together create new meanings (Biggs, 1999; Falk and Dierking, 2000; Goodrum, 2007; Preston and Rooy, 2007).

Falk and Dierking (2000) and Paris (1997) agreed that students often enjoy learning more when they can learn in settings where they have a choice and some control over their learning. They consider school gardens an ideal learning environment. For Tal (2012), learning that occurs in settings such as school gardens enriches students' learning experiences, encourages lifelong learning, and introduces youngsters to possible future careers they may not otherwise consider from within the boundaries of the traditional curriculum (Bamberger and Tal, 2007).

As informal settings are idiosyncratic and allow students greater autonomy over their learning, student learning in these environments is also mediated by each student's personal and social contexts. Rauschenbach et al. (2004) use the terms "voluntary" and "affordance" to describe this type of socially mediated, student-directed learning (p. 29). Several studies (e.g., Falk and Dierking, 2000, and Paris, 1997) show that, for students, learning in out-of-classroom environments is intrinsically social because they can work together in various group configurations (ranging from pairs to relatively large groups) to share information, contribute their skills, and collectively find answers to what are often complex issues. Griffin (2007) and Leinhardt and Gregg (2002) discussed what they call students' "learning talk," noting that up to $89 \%$ of student conversations in settings such as school gardens consist of this type of talk.

Such learning focuses our attention on the social processes operating in these out of classroom settings. This leads to sociocultural and social constructivist perspectives of learning wherein students construct their knowledge through collaborative engagement with one another. Among the many theorists in these fields are Lave and Wenger (1991) and Rogoff (1991; 1995), for whom learning is also an outcome of social participation.

\section{METHODOLOGY}

Before this study, the concept of a school garden was unknown in Oman, but six schools agreed to participate because they had at least one teacher willing and able to oversee the management of the school garden. Two of the schools were co-educational Grades 1-4 schools, and four were single-sex, Grade 5-10 schools (two male and two female). This article reports on the findings from the Grade 1 to 4 schools, specifically Grade 2.

The schools, located within three geographical regions of Oman- Muscat (Seeb), Al-Dakhlyai (Nizwa and Samail), and Batinah South (Wadi Al-Maael) - were each provided with the assistance of advisors employed by the study to report to the principal researchers, advised on maintaining the school gardens, provided advice on pedagogy, and collected data during the project (Ambusaidi et al., 2015). 
The project itself employed a quasi-experimental design, using mixed-methods and encompassing several phases:

\section{Phase 1: Pre-Intervention Data Collection}

A questionnaire was administered to Grade 2 student participants before their involvement in the school garden project; some of the items were adapted from existing questionnaires employed by Block and Johnson (2009). The questionnaire had three sections:

- Science content knowledge: 18 multiple-choice items

- Science process skills: 16 multiple-choice items covering four skill sets each made up of four items - observation, prediction, measuring, and classification skills

- Attitudes toward healthy dietary habits, science, and gardening: 27 Likert-type items with three response options (agree, disagree, and neutral).

Due to the young age of the students, they were asked to depict their responses symbolically, as shown in Figure 1.

\section{Phase 2: Establishing the School Garden}

The researchers worked with each of the schools to establish not only the gardens but also compost bins to provide an ongoing source of growing medium for each garden (Figures 2 and 3).

\section{Phase 3: Linking Gardening to the School Curriculum}

An important component of the research was to link the school garden activities to Oman's formal curriculum, especially the

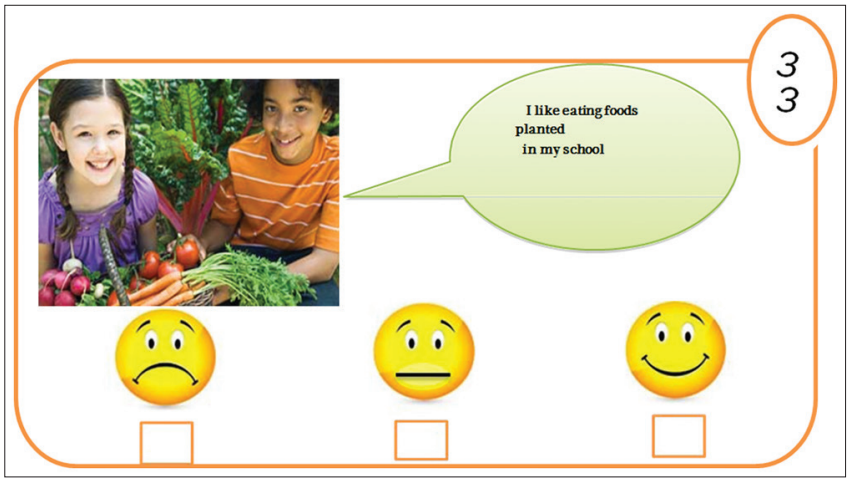

Figure 1: An item from the attitudinal survey showing the pictorial Likert scale for Grade 2 students

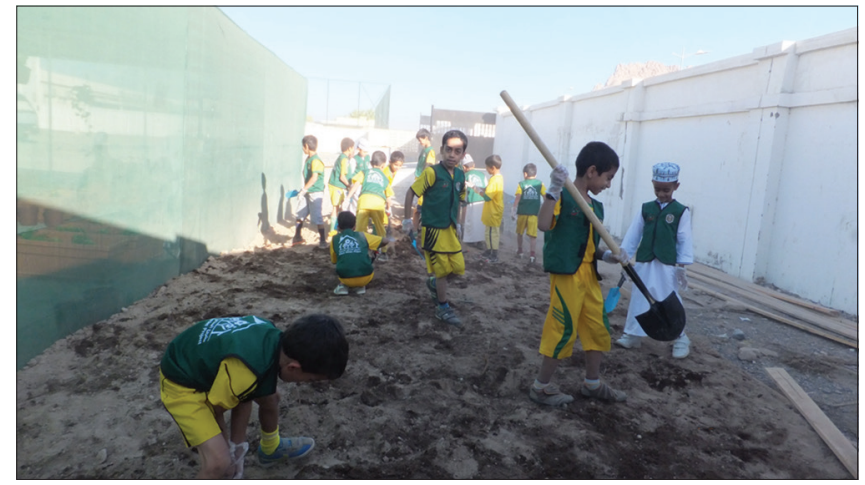

Figure 2: Grade 2 students preparing the soil in a school garden science curriculum, which incorporates environmental and health education. In collaboration with the teachers and after conducting an in-depth analysis of the Omani curriculum from Grades 1 to 7, the researchers developed a series of draft activities and produced unit booklets that adapted existing published activities to the Omani context. They also developed new activities to match curricular outcomes. The activities included examining and observing the main parts of plants, growing plants for seeds and cuttings, and measuring plant height over time (Figure 4).

\section{Phase 4: The Intervention}

Once preliminary data had been collected, linked activities agreed on, and the school gardens established, the researchers provided participating teachers with intensive training in how to use the activities; that is, the researchers modeled some of the activities with the students and teachers to give them the opportunity to experience the garden as a learning resource from a learner's perspective.

As part of this professional development, teachers spent a full day at the Agriculture Research Center (Station) of Sultan Qaboos University. Parents and other members of the local community were also invited to an open day at the center. During their time at the center, teachers, parents, and community members learned about the nutritional and health benefits of growing and consuming their own vegetables and

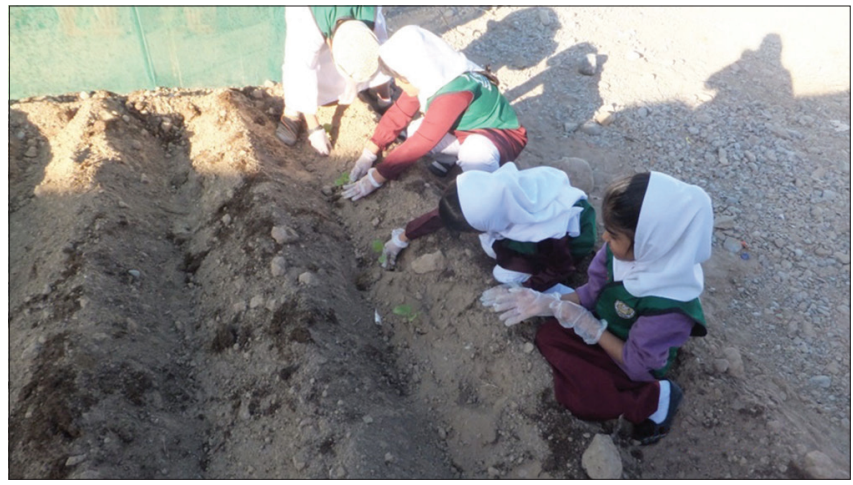

Figure 3: Grade 2 students planting seedlings in a school garden

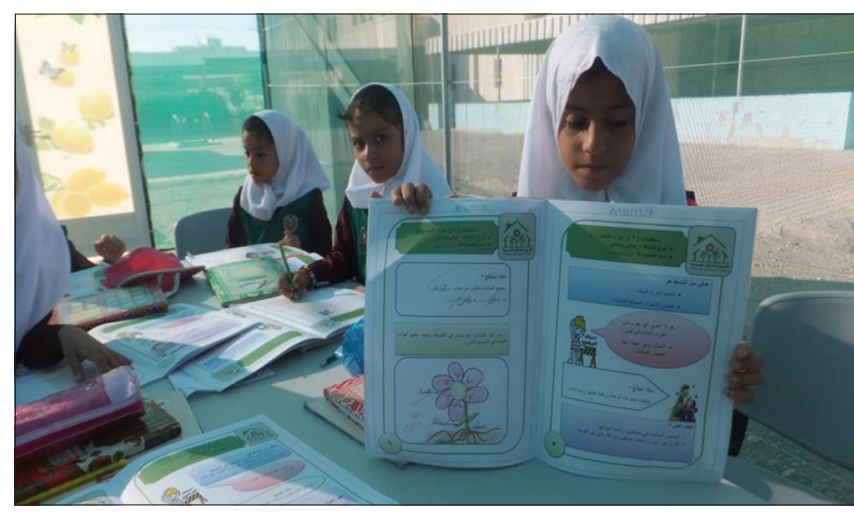

Figure 4: A student displaying her work as part of a science lesson in a school garden 
received guidance on how to establish small-scale vegetable gardens in their own localities.

Meanwhile, the same curriculum content covered in the experimental schools was delivered in four control schools. However, the activities in the control schools were delivered without the use of school gardens as a resource and in keeping with the traditional guided inquiry method.

Phase 5: Post-Intervention Data Collection and Analysis After 3 months of working on garden activities (Phase 4), participating students again completed the questionnaire administered in Phase 1. The researchers also interviewed 20 participating students from the experimental group, their parents, and two of the participating Grade 2 teachers. Given the young age of the Grade 2 students, they were asked relatively straightforward questions such as what they liked and disliked about garden-related studying and doing activities; if they could recall anything specific, they had learned through their activities in the garden; and if they would like to continue studying in the garden. The brief interviews with the parents of the 20 students asked them if and what their children had said at home about the school garden and if the experience of gardening had impacted in any way on their dietary habits. Teachers were asked to reflect on their experience of the school garden approach. The interview data were used to help with data triangulation.

\section{Analysis of the Quantitative Data}

Analysis of covariance tests was conducted to compare the effectiveness of the school gardening intervention that was designed with the intention of improving students' science process skills and science content knowledge as well as their attitudes toward science, their gardening skills, and their healthy eating habits. The independent variable was the school gardening intervention: The experimental group had access to the intervention while the control group did not. The dependent variable comprised scores on a set of three instruments designed to test science content knowledge, science process skills and attitudes toward science, and gardening and healthy dietary habits.

These instruments were administered after the intervention was completed. Students' scores on the pre-intervention administration of the instruments were used as the covariate in this analysis. Preliminary checks were carried out to ensure that there was no violation of the assumptions of normality, linearity, homogeneity of variances, homogeneity of regression slopes, and reliable measurement of the covariate.

\section{Analysis of Qualitative Data}

The interviews with students, parents, and teachers were digitally recorded, transcribed, and translated from Arabic to English. The responses were then coded into themes, based largely on the questions. The transcribed texts were lightly edited (e.g., removal of repeated words and filler words such as "um" and "ah"), but care was taken not to change the sense of the discourse.

\section{FINDINGS AND DISCUSSION}

\section{Science Content Knowledge}

After adjusting for pre-intervention scores, the researchers found no significant interaction effect: $F(1,274)=0.466$, $\mathrm{p}<0.496$, with a small effect size (partial eta squared $=0.002$ ).

In regard to the main effects, a statistically significant effect was noted for gender: $F(1,274)=8.107, p<0.005$, with a small effect size (partial eta squared $=0.029$ ). However, no such effect was observed for group (access to gardening intervention or not): $\mathrm{F}(1,274)=0.182, \mathrm{p}<0.67$, with a small effect size (partial eta squared $=0.001)($ Table 1$)$.

The results suggest that the gardening intervention had more of an influence on female students' science content knowledge than on male students' science content knowledge. Table 1 sets out the control and experimental groups' pre- and postintervention mean scores on the science content knowledge test by gender and group.

\section{Science Skills}

After adjusting for pre-intervention scores, the researchers found no significant interaction effect for science process skills: $\mathrm{F}(1,267)=2.245, \mathrm{p}<0.135$, with a small effect size (partial eta squared $=0.008$ ).

As regard to the main effects, a statistically significant difference was noted for gender in favor of female students in the total mean score on the science process skills test: $\mathrm{F}(1,267)=22.239, \mathrm{p}<0.001$, with a medium effect size ( artial eta squared $=0.08$ ). A similar result was noted in favor

Table 1: Science content knowledge: Pre-test and post-test means by gender and group

\begin{tabular}{llcc}
\hline Gender & Group & Pre-test mean & Post-test mean \\
\hline Male & Experimental (intervention) & 11.784 & 13.162 \\
& Control (non-intervention) & 12.568 & 13.114 \\
Female & Total & 12.21 & 13.136 \\
& Experimental (intervention) & 10.672 & 13.934 \\
& Control (non-intervention) & 11.321 & 14.393 \\
Total & Total & 10.983 & 14.154 \\
& Experimental (intervention) & 11.282 & 13.511 \\
& Control (non-intervention) & 12.083 & 13.611 \\
\end{tabular}


of females in the specific scientific skills of (1) prediction, F $(1,267)=4.358, \mathrm{p}<0.038$, with a small effect size (partial eta squared $=.02)$; (2) measurement, $\mathrm{F}(1,267)=12.211, \mathrm{p}<0.001$, with a small effect size (partial eta squared $=0.04$ ); and (3) classification, $\mathrm{F}(1,267)=17.969, \mathrm{p}<.001$, with a medium effect size (partial eta squared $=0.06)($ Table 2$)$.

Table 2: Science skills: Pre-test and post-test means by gender and group

\begin{tabular}{|c|c|c|c|c|}
\hline Gender & Group & Pre-test mean & Post-test mean & $n$ \\
\hline \multicolumn{5}{|c|}{ Total skill score } \\
\hline \multirow[t]{3}{*}{ Male } & Experimental (intervention) & 8.015 & 8.829 & 69 \\
\hline & Control (non-intervention) & 7.575 & 9.3 & 87 \\
\hline & Total & 7.769 & 9.094 & 156 \\
\hline \multirow[t]{3}{*}{ Female } & Experimental (intervention) & 7.831 & 10.672 & 59 \\
\hline & Control (non-intervention) & 7.9818 & 10.255 & 55 \\
\hline & Total & 7.904 & 10.474 & 114 \\
\hline \multirow[t]{3}{*}{ Total } & Experimental (intervention) & 7.923 & 9.687 & 128 \\
\hline & Control (non-intervention) & 7.732 & 9.662 & 142 \\
\hline & Total & 7.826 & 9.674 & 270 \\
\hline \multicolumn{5}{|c|}{ Observation skills } \\
\hline \multirow[t]{3}{*}{ Male } & Experimental (intervention) & 1.696 & 1.7 & 69 \\
\hline & Control (non-intervention) & 1.805 & 1.811 & 87 \\
\hline & Total & 1.756 & 1.763 & 156 \\
\hline \multirow[t]{3}{*}{ Female } & Experimental (intervention) & 1.593 & 1.934 & 59 \\
\hline & Control (non-intervention) & 1.709 & 1.855 & 55 \\
\hline & Total & 1.649 & 1.897 & 114 \\
\hline \multirow[t]{3}{*}{ Total } & Experimental (intervention) & 1.648 & 1.809 & 128 \\
\hline & Control (non-intervention) & 1.768 & 1.828 & 142 \\
\hline & Total & 1.711 & 1.819 & 270 \\
\hline \multicolumn{5}{|c|}{ Prediction skills } \\
\hline \multirow[t]{3}{*}{ Male } & Experimental (intervention) & 1.551 & 2.157 & 69 \\
\hline & Control (non-intervention) & 1.345 & 2.022 & 87 \\
\hline & Total & 1.436 & 2.081 & 156 \\
\hline \multirow[t]{3}{*}{ Female } & Experimental (intervention) & 1.271 & 2.492 & 59 \\
\hline & Control (non-intervention) & 1.436 & 2.2 & 55 \\
\hline & Total & 1.351 & 2.353 & 114 \\
\hline \multirow[t]{3}{*}{ Total } & Experimental (intervention) & 1.422 & 2.313 & 128 \\
\hline & Control (non-intervention) & 1.38 & 2.09 & 142 \\
\hline & Total & 1.4 & 2.196 & 270 \\
\hline \multicolumn{5}{|c|}{ Measurement skills } \\
\hline \multirow[t]{3}{*}{ Male } & Experimental (intervention) & 2.783 & 2.814 & 69 \\
\hline & Control (non-intervention) & 2.471 & 2.978 & 87 \\
\hline & Total & 2.61 & 2.906 & 156 \\
\hline \multirow[t]{3}{*}{ Female } & Experimental (intervention) & 2.56 & 3.361 & 59 \\
\hline & Control (non-intervention) & 2.582 & 3.2 & 55 \\
\hline & Total & 2.57 & 3.285 & 114 \\
\hline \multirow[t]{3}{*}{ Total } & Experimental (intervention) & 2.68 & 3.069 & 128 \\
\hline & Control (non-intervention) & 2.514 & 3.062 & 142 \\
\hline & Total & 2.593 & 3.065 & 270 \\
\hline \multicolumn{5}{|c|}{ Classification skills } \\
\hline \multirow[t]{3}{*}{ Male } & Experimental (intervention) & 1.986 & 2.157 & 69 \\
\hline & Control (non-intervention) & 1.954 & 2.494 & 87 \\
\hline & Total & 1.968 & 2.346 & 156 \\
\hline \multirow[t]{3}{*}{ Female } & Experimental (intervention) & 2.407 & 2.879 & 59 \\
\hline & Control (non-intervention) & 2.255 & 3 & 55 \\
\hline & Total & 2.333 & 2.938 & 114 \\
\hline \multirow[t]{3}{*}{ Total } & Experimental (intervention) & 2.18 & 2.484 & 128 \\
\hline & Control (non-intervention) & 2.07 & 2.688 & 142 \\
\hline & Total & 2.122 & 2.592 & 270 \\
\hline
\end{tabular}


The results suggest that the gardening intervention had a stronger influence on female students' science process skills than on male students' science process skills. Table 2 sets out the control and experimental groups' pre- and postintervention mean scores on the science skills test by gender and group.

\section{Attitudinal Survey}

After adjusting for pre-intervention scores, the researchers found a significant interaction effect for the attitude to gardening subscale in favor of female students in the experimental group: $\mathrm{F}(1,261)=4.462$, $\mathrm{p}<0.036$, with a small effect size (partial eta squared $=0.02$ ). A statistically significant difference was also noted for gender in favor of females on the attitudes test: $F(1,261)=57.349, \mathrm{p}<0.001$, with a large effect size (partial eta squared $=0.18)($ Table 3$)$.

A similar result was observed in favor of females for the subscales of (1) attitude to healthy dietary habits, $\mathrm{F}(1,261)=45.408, \mathrm{p}<0.001$, with a large effect size (partial eta squared $=0.15) ;(2)$ attitude to science, $\mathrm{F}(1,261)=21.353$, $\mathrm{p}<0.001$, with a medium effect size (partial eta squared $=$ $0.08)$; and (3) attitude to gardening, $\mathrm{F}(1,261)=36.123$, $\mathrm{p}$ $<0.001$, with a large effect size (partial eta squared $=0.12$ ). A statistically significant difference was also noted in favor of the experimental group but only for the subscale of attitude

\section{Table 3: Attitudinal survey: Pre-test and post-test means by gender and group}

\begin{tabular}{|c|c|c|c|c|}
\hline Gender & Group & Pre-test mean & Post-test mean & n \\
\hline \multicolumn{5}{|c|}{ Overall attitude } \\
\hline \multirow[t]{3}{*}{ Male } & Experimental (intervention) & 1.567 & 1.521 & 67 \\
\hline & Control (non-intervention) & 1.554 & 1.462 & 86 \\
\hline & Total & 1.556 & 1.488 & 153 \\
\hline \multirow[t]{3}{*}{ Female } & Experimental (intervention) & 1.894 & 1.926 & 62 \\
\hline & Control (non-intervention) & 1.8 & 1.88 & 53 \\
\hline & Total & 1.851 & 1.904 & 115 \\
\hline \multirow[t]{3}{*}{ Total } & Experimental (intervention) & 1.724 & 1.716 & 129 \\
\hline & Control (non-intervention) & 1.649 & 1.624 & 139 \\
\hline & Total & 1.685 & 1.668 & 268 \\
\hline \multicolumn{5}{|c|}{ Attitude to healthy dietary habits } \\
\hline \multirow[t]{3}{*}{ Male } & Experimental (intervention) & 1.578 & 1.561 & 67 \\
\hline & Control (non-intervention) & 1.539 & 1.51 & 86 \\
\hline & Total & 1.555 & 1.532 & 153 \\
\hline \multirow[t]{3}{*}{ Female } & Experimental (intervention) & 1.83 & 2.078 & 62 \\
\hline & Control (non-intervention) & 1.9 & 1.864 & 53 \\
\hline & Total & 1.862 & 1.978 & 115 \\
\hline \multirow[t]{3}{*}{ Total } & Experimental (intervention) & 1.699 & 1.809 & 129 \\
\hline & Control (non-intervention) & 1.676 & 1.647 & 139 \\
\hline & Total & 1.687 & 1.725 & 268 \\
\hline \multicolumn{5}{|c|}{ Attitude to science } \\
\hline \multirow[t]{3}{*}{ Male } & Experimental (intervention) & 1.628 & 1.671 & 67 \\
\hline & Control (non-intervention) & 1.614 & 1.564 & 86 \\
\hline & Total & 1.62 & 1.611 & 153 \\
\hline \multirow[t]{3}{*}{ Female } & Experimental (intervention) & 1.86 & 1.949 & 62 \\
\hline & Control (non-intervention) & 1.747 & 1.914 & 53 \\
\hline & Total & 1.808 & 1.932 & 115 \\
\hline \multirow[t]{3}{*}{ Total } & Experimental (intervention) & 1.74 & 1.804 & 129 \\
\hline & Control (non-intervention) & 1.665 & 1.7 & 139 \\
\hline & Total & 1.7 & 1.75 & 268 \\
\hline \multicolumn{5}{|c|}{ Attitude to gardening } \\
\hline \multirow[t]{3}{*}{ Male } & Experimental (intervention) & 1.51 & 1.354 & 67 \\
\hline & Control (non-intervention) & 1.511 & 1.33 & 86 \\
\hline & Total & 1.511 & 1.341 & 153 \\
\hline \multirow[t]{3}{*}{ Female } & Experimental (intervention) & 1.975 & 1.783 & 62 \\
\hline & Control (non-intervention) & 1.774 & 1.859 & 53 \\
\hline & Total & 1.882 & 1.819 & 115 \\
\hline \multirow[t]{3}{*}{ Total } & Experimental (intervention) & 1.733 & 1.56 & 129 \\
\hline & Control (non-intervention) & 1.611 & 1.536 & 139 \\
\hline & Total & 1.67 & 1.548 & 268 \\
\hline
\end{tabular}


to healthy dietary habits: $\mathrm{F}(1,261)=7.02, \mathrm{p}<0.009$, with a small effect size (partial eta squared $=0.03$ ).

The results suggest that the gardening intervention had more of an impact on female students than on male students in terms of overall attitude as well as attitudes within the three subscales. It also appears that the intervention had a greater influence on the experimental group than on the control group in terms of attitude to healthy dietary habits. The results, furthermore, indicate that the gardening intervention had more of an impact, with respect to attitude to gardening, on the females in the experimental group than on the females and males in all other groups. Table 3 sets out the control and experimental groups' pre- and post-intervention mean scores on the attitudinal survey by gender and group.

\section{Students' Views}

The students were asked what they had enjoyed about working in the school garden, what they felt that they had learned, and if there was anything, they did not like about the experience. All students appeared to enjoy the experience, mainly, it seemed, because it was something different. Remaz (all names are pseudonyms) commented that she liked the change from being in the classroom: "It's great to do something new and different and I love the nature... A lot of it attracted me - the smell of fruits and pepper - and I even couldn't wait to have a taste of my classmates' fruits."

Others also enjoyed the esthetics. Maha, for example, commented: "I love flowers, because they smell beautiful and give us positive feelings." This sense of well-being was also commented on by Al Ayham: “...it relaxes me, and I feel calmer in the garden." This sense of calm was also reported by one of the interviewed parents of a different child.

When asked that what they had learned from studying in the school garden, most students referred to growing and caring for their plants as the key learning experience. Abdullah said that he had learned how to plant plants and about different types of soil, while Faris stated that he had learned that agriculture gives us fruits and oxygen.

A small number of students expressed some negative views of the school gardens, but these related to a dislike of digging in the soil and getting their clothes dirty. Remaz, for example, commented that she disliked the garden when she got dirt on her clothes but then went on to say, "But it's not that discomforting."

\section{Parents' Views}

The parents of all the students interviewed were asked two questions. The first asked them if their children talked at home about their study activities in the school garden and what they had said. The second question asked parents if they had noticed any change in their children's dietary habits, particularly a desire to eat more fruit and vegetables.

All 20 parents reported that their children spoke positively about their activities in the school gardens and in some cases were quite specific about what they did and what they enjoyed. The following sample of quotes illustrates what the parents said:

"Of course my daughter would talk about the garden a lot and follow (ed) up on her plants eagerly and... (her) sudden interest in agriculture. I never noticed my daughter's love for plants till this project; she would say that she couldn't wait for the science class so that she might be able to go to the school garden."

"Yes, she spoke of her experience in the school garden with happiness and excitement about what they planted and what (would) grow and the safety precautions that were taken during the lessons in the school garden and the work she did with her classmates and teacher."

"Yes, he would constantly talk about all that he did in the school garden from fertilizing to planting to harvesting."

"Yes, he would constantly talk about sitting in the garden and how calm he felt there and (about) him working with his classmates."

Most of the parents reported a desire on the part of their children to consume more fruit and vegetables. One parent said of their son "Yes, his appetite toward vegetables increased, mainly for the vegetables in the school garden, such as tomatoes and others." Another commented on their daughter's newfound enthusiasm for eating vegetables "Yes, she loves vegetables a lot. She used to love fruit and kept away from vegetables, but after the school garden she has learned the value (of eating vegetables)." A third parent said that their daughter had developed a greater interest in eating fruit and vegetables "Not just her appetite but she also wants to know what types of fruit and vegetables are around - the names of the plants and if (they) can be grown in Oman and when they can be grown."

\section{Teachers' Views}

The teachers were asked to provide their general views about the gardening project. They were very positive about using the garden as a resource for teaching science and reported favorably about the impact it had on their students. According to Amal:

“... The project helped to develop students' experiences in cultivation of seeds and seedlings and follow-up until the yield and harvest of fruit themselves. These things will instill confidence and responsibility... (in) these young students and (will help them) rely on themselves in watering plants... (which they) pursued with great interest and enthusiasm, thus instilling in them the importance of local fruit and vegetables... (compared to) those imported from other countries."

The same teacher went on to comment on statements she had received from parents of her students:

"Some mothers indicated that they observed changes in their children's behavior in terms of helping their parents at home, such as watering plants with enthusiasm, and talked about growth of plants and their eagerness to harvest fruit. Some 
mothers also added that their children followed healthy feeding patterns to eat vegetables and fruit and had the desire to prepare fruit salad in an attractive way and also prepared fresh juices. Finally, the mothers recommended the importance of school gardens in all the Sultanate's schools due to what they observed in their children's behavioral aspects."

Safiya commented that the garden had offered a range of benefits for the school and the students: “... They (the students) were very enthusiastic to work in the school garden and were very engaged in the science classes (so much so) that they would try to substitute any other classes, i.e. math class, for a science class." She claimed that the garden had allowed the students to study the Grade 2 unit on "plants" in a far more practical manner than previously and that she had been able to make clear for students the link between eating vegetables and improved health. The students, she said, had sold the produce they had grown to parents and other teachers.

Overall, Safiya thought that it was easier for students to achieve learning outcomes when working in the garden environment "It felt great because I felt like I accomplished the lesson better in the garden than if they were in the classroom and achieved the lesson objective more clearly and faster." She attributed some of this benefit to the change in the learning environment “... it's vital for the students and teachers to be able to change routines, and the school garden brings a different and fruitful atmosphere and gives them the practical experience; it will help achieve goals and make teaching and learning fun for both teachers and students."

Both teachers, however, raised concerns about the longer term maintenance of the garden given the harsh climate in Oman and the difficulty of looking after it over the vacation periods. One garden was showing evidence of pest problems, although these problems in themselves have the potential to provide teaching and learning opportunities if teachers are made aware of how to do this.

\section{CONCLUSIONS}

This research project was part of a larger pilot study focused on introducing school gardens to Oman at the Grade 7 and Grade 2 levels. The overarching research question that informed the study was: Can school gardens be an effective pedagogical resource in schools within the Sultanate of Oman? The findings have been treated tentatively because this was a pilot study, the intervention was a relatively short one, and the initial enthusiasm for the project among both students and staff might wane in the longer term. However, as with the findings for the Grade 7 component of the project (Ambusaidi et al., 2018), those for Grade 2 indicate that there could be benefits in adopting school gardens as teaching resources in Oman.

The quantitative findings for this cohort of Grade 2 students suggested that the gardening intervention had a greater positive impact on female students than on male students. This pattern was evident for all three tested areas: Science skills, science content knowledge, and attitudes toward healthy dietary habits, science, and gardening. The attitudinal survey also indicated that the students in the experimental group were statistically more inclined to adopt healthy dietary habits than those in the control group and that within the experimental group this effect was greater among female than among male students.

The qualitative findings were encouraging, as the responses to the gardening project from students, teachers, and parents were consistently positive. Young students are almost inevitably keen to please when asked if they like something, and all the students indeed claimed that they enjoyed the experience of working in the garden. However, most could specify what they particularly enjoyed about the school garden, which was generally the esthetics, such as calm, fresh air, and the smell of the fruit, flowers, and vegetables. Many of the students could also point to what they had learned, at least in general terms. The learning that they specified included planting vegetables, soil types, and growing and looking after plants. These results were confirmed by interviews with parents who verified the general enthusiasm shown by the students for the school gardens by relating the students' conversations at home. Perhaps, most encouraging were reports from those parents who said that their children had changed their dietary habits to encompass healthier choices and were now eating more fruit and vegetables.

This finding supports the results from the quantitative component of the study on dietary attitudes and is in keeping with the findings of a study conducted in the UK by Passy et al. (2011). They reported that students engaged in school gardening projects developed a positive attitude to healthy food choices and became more willing to try new vegetables and incorporate them into their diet.

Results for Grade 2 differed from the findings for Grade 7 students, where there was little evidence of dietary improvement, which suggests that stimulating dietary change may be easier among younger children in Oman. There was no scope to follow up on these reported dietary changes to see if they were sustained in the longer term, but it is encouraging that studying in the school garden and growing their own fruit and vegetables appeared to have impacted positively on these young children's dietary habits at least in the short term.

Another positive finding concerned the apparent affective benefits for students of studying in the garden. Several students said that they experienced a sense of calm while studying, a finding supported by those parents who said their children had told them of their feelings of calm. A finding such as this may point to the therapeutic associations of horticulture reported by Smith and Aldous (1994).

Overall, the findings of this study suggest that, for Grade 2 students in Oman, school gardens may be an effective resource. However, a longer-term trial with a wider range of schools is required before any national policy can be developed for school gardens. In addition, establishing and maintaining school gardens across Oman could involve some major hurdles. As Ambusaidi et al. (2018) point out, much of Oman has a 
harsh arid climate where soil and water need to be brought in to establish gardens. Doing this is costly but would have been possible when oil prices were high. In recent years, the price of oil has fallen from around US\$120 per barrel in 2012 to around US\$50 per barrel at the time of writing, resulting in many projects in Oman and other Gulf States being put on hold. Despite this, exploring the use of hydroponics in schools as a less costly option for small-scale gardening might be worthwhile because hydroponics eliminates the need for purchasing soil and generally reduces the number of pest infestations that can occur.

\section{ACKNOWLEDGMENT}

This project was funded by a grant from the Omani Research Council.

\section{REFERENCES}

Al Riyamai, A., \& Afifi, M. (2003). Clustering of cardiovascular risk factors among Omani adults. Eastern Mediterranean Health Journal, 9(5-6), 893-903.

Al Shaibany, S. (2011). "Parents Declare 'War' on Junk Food in Schools". Times of Oman.

Al-Moosa, S., Allin, J.N., Al-Lawiti, J., \& Mossialos, E. (2006). Diabetes and urbanization in the Omani population: An analysis of national survey data. Population Health Metrics, 4(5), 1-8.

Ambusaidi, A., Al-Yahyai, R., \& Taylor, N. (2015). Establishing and researching school gardens in Oman as a resource for improving education and health outcomes. Economic and Environmental Studies, 15(4), 415-431.

Ambusaidi, A., Al-Yahyai, R., Taylor, N., \& Taylor, S. (2018). Introducing school gardens to the Omani context: A preliminary study with Grade 7 classes. Eurasia Journal of Mathematics, Science and Technology Education, 14(3), 1043-1055.

Bamberger, Y., \& Tal, T. (2006). Learning in a personal context: Levels of choice in a free choice-learning environment at science and natural history museums. Science Education, 91(1), 75-95.

Biggs, J. (1999). Teaching for Quality Learning at University. Buckingham, UK: Society of Research into Higher Education (SRHE) and Open University.

Block, K., \& Johnson, B. (2009). Evaluation of the Stephanie Alexander Kitchen Garden Program: Final Report. Melbourne, VIC: University of Melbourne.

Bowker, R., \& Tearle, P. (2007). Gardening as a learning environment: A study of children's perceptions and understanding of school gardens as part of an international project. Learning Environment Research, $10(2), 83-100$.

Central Intelligence Agency (CIA). (2016). Middle East: Oman, in CIA World Factbook. Washington, DC. Available from: https://www.cia.gov/ library/publications/the-world-factbook/geos/mu.html. [Last retrieved on 2014 Nov 18].

Clark, M. (1977). The learning process: Why youth gardening? In: Shaucha, B., (Ed.), The Long View Ahead: Civic Garden Centers Servicing People, Plants _ Plants People. Bloomington, IN: National Civic Gardens Center Inc., University of Indiana Publications. p92-96.

Crisp, B., Swerrissen, H., \& Duckett, S. (2000). Four approaches to capacity building in health: Consequences for measurement and accountability. Health Promotion International, 15(2), 99-107.

Crystal, J.A., \& Peterson, J.E. (2016). Oman. In: Encyclopaedia Britannica. Available from: https://www.britannica.com/place/Oman. [Last retrieved on 2014 Nov 18].

Elzaanen, J. (2010). Effectiveness of suggested garden-based science unit as an entrance on seventh grade students' achievement and improving their understanding of science processes in the Gaza Strip. Journal of Islamic University (Human Studies Series), 18(1), 271-309.
Falk, J., \& Dierking, L. (2000). Learning from Museum: Visitor Experiences and the Making of Meaning. Walnut Creek, CA: AltaMira Press.

Goodrum, D. (2007). Teaching strategies for classroom learning. In: Dawson, V., \& Venville, G., (Eds.), The Art of Teaching Primary Science. Crows Nest, NSW, Australia: Allen and Unwin. p108-126.

Graham, H., Beall, D., Lussier, M., Mclaughlin, P., \& Zidenberg-Cher, S. (2005). Use of school gardens in academic instruction. Journal of Nutrition Education and Behavior, 37(3), 147-151.

Griffin, J. (2004). Research on students and museums: Looking more closely at the students in school groups. Science Education, 88(Supplement 1), S59-S70.

Griffin, J. (2007). Students, teachers and museums: Towards an intertwined learning circle. In: J. Falk, L. Dierking, \& S. Foutz, (Eds.). In principle, in practice: Museums as learning institutions. 31-42. Lanham, MD: AltaMira.

Hawe, P., \& Shiell, A. (2000). Social capital and health promotion: A review. Social Science Medicine, 51(6), 871-885.

Hoffman, A., Trepagnier, B., Cruz, A., \& Thompson, D. (2004). Gardening activity as an effective measure in improving self-efficacy and selfesteem: Community college students learning effective living skills. The Community College Enterprise, 9, 231-239.

Knai, C., Pomerleau, J., Lock, K., \& McKee, M. (2006). Getting children to eat more fruit and vegetables: A systematic review. Preventative Medicine, 42(2), 85-95.

Lave, J., \& Wenger, E. (1991). Situated Learning: Legitimate Peripheral Participation. Cambridge, UK: Cambridge University Press.

Lavin, A., Shapiron, G., \& Weil, K. (1992). Creating an agenda for schoolbased health promotion: A review of 25 selected projects. Journal of School Health, 62(6), 212-228.

Leinhardt, G., \& Gregg, S. (2002). Burning buses, burning crosses: Student teachers see civil rights. In: Leinhardt, G., Crowley, K., \& Knutson, K., (Eds.), Learning Conversation in Museums. Mahwah, NJ: Lawrence Erlbaum. p139-166.

Lineberger, S., \& Zajicek. J. (2000). School gardens: Can a hands-on teaching tool affect students' attitudes and behaviors regarding fruit and vegetables. Hort Technology, 10(3), 593-597.

Marturano, A. (1999). The educational roots of garden-based instructions and contemporary gateways to gardening with children. Kindergarten Education: Theory, Research and Practice, 4(1), 55-70.

Montessori, M. (1964). The Montessori Method. New York: Schocken Books.

Morgan, P., Warren, J., Lubans, D., Saunders, K., Quick, G.I., \& Collins, C. (2010). The impact of nutrition education with and without a school garden on the knowledge, vegetable intake and preferences and the quality of school life among primary-school students. Public Health Nutrition, 13(11), 1931-1940.

Morris, J.L., Briggs, M., \& Zidenberg-Cher, S. (2002). Nutrition to grow on: A garden-enhanced nutrition education curriculum for upper-elementary school children. Journal of Nutrition Education and Behavior, 34(3), 175-176.

Omani Ministry of Agriculture and Fisheries (2014). Agricultural Statistical Census. Available from: http://www.mafstat.gov.com. [Last retrieved on 2014 Nov 18].

Ozer, E. (2007). The effects of school gardens on students and schools: Conceptualization and considerations for maximizing healthy development. Health Education and Behavior, 34(6), 846-863.

Paris, S. (1997). Situated motivation and informal learning. Journal of Museum Education, 22(2-3), 22-26.

Passy, R., Morris, M., \& Reed, F. (2011). Impact of School Gardening on Learning: Final Report to the Royal Horticultural Society. Slough, UK: National Foundation for Educational Research.

Preston, C., \& Rooy, V. (2007). Planning to teach primary science. In: Dawson, V., \& Venville, G., (Eds.), The Art of Teaching Primary Science. Crows Nest, NSW, Australia: Allen and Unwin. p87-107.

Rauschenbach, T., Leu, H., Lingenauber, S., Mack, W, Schilling, M, Schneider, K., \& Züchner, I. (2004). Non-formale und Informelle BILDUNG im Kindes- und Jugendalter [Non-formal and formal education in childhood and adolescence]. Berlin, Germany: Ministry of Education and Research.

Rogoff, B. (1995). Observing sociocultural activity on three planes: Participatory appropriation, guided participation and apprenticeship. 
In: Wertsch, J., Rio, P., \& Alvarez, A., (Eds.), Sociocultural Studies of Mind. Cambridge, UK: Cambridge University Press. p139-164.

Rogoff, B. (1991). Social interaction as apprenticeship in thinking: Guided participation in spatial planning. In: Resnick, L., Levine, J., \& Teasley, S., (Eds.), Perspectives on Socially Shared Cognition. Washington, DC: American Psychological Association. p349-364.

Scott, P. (1998). Teacher talk and meaning making in science classrooms: A Vygotskian analysis and review. Studies in Science Education, $32,45-80$.

Sheffield, B. (1992). The Affective and Cognitive Effects of an Interdisciplinary Garden-based Curriculum on Underachieving Elementary Students. (Unpublished doctoral dissertation, University of South Carolina, Columbia, SC).

Smith, V., \& Aldous, D. (1994). The effects of therapeutic horticulture on the self-concept of the mildly intellectually disabled student. In: Lindsey, F., \& Rice, J. (Eds.), The Healing Dimensions of People-plant Relations.
Davis, CA: Center of Design Research, University of California at Davis. UC Davis, CA: Centre or Design Research. p215-221.

Staff Reporter. (2011). Food Imports by Oman Set to Grow to \$4.8bn by 2020. Oman Daily Observer. Available from: http://www.pressreader. com/oman/oman-daily-observer/20111109/281870115230033. [Last retrieved on 2014 Nov 18].

Tal, R. (2012). Out-of-school: Learning experiences, teaching and students' learning. In: Fraser, B., Tobin, K., \& McRobbie. C., (Eds.), Second International Handbook of Science Education. Vol. 2. Dordrecht, The Netherlands: Springer. p1109-1122.

Waliczek, T., Bradley, J., \& Zajicek, J. (2001). The effect of school gardens on children's interpersonal relationships and attitudes towards school Hort Technology, 11(30), 466-468.

World Health Organization. (2000). The world Health Report 2000. Health Systems: IMPROVING Performance. Available from http://www.who. int/whr/2000/en/whr00 en.pdf. [Last retrieved on 2014 Nov 18]. 